\title{
Investigating the origins and evolution of a glyphosate-resistant weed invasion in South America
}

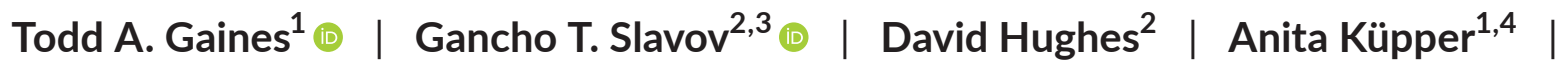

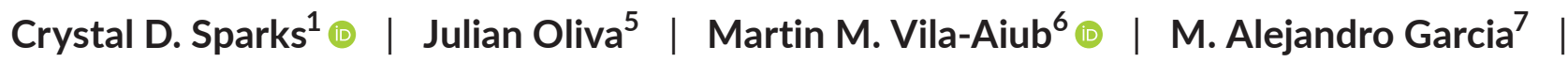 \\ Aldo Merotto $\mathrm{Jr}^{8}$ | Paul Neve 2,9
}

${ }^{1}$ Department of Agricultural Biology, Colorado State University, Fort Collins, Colorado, USA

${ }^{2}$ Rothamsted Research, West Common, Harpenden, Hertfordshire, UK

${ }^{3}$ Scion, Rotorua, New Zealand

${ }^{4}$ Crop Science Division, Weed Control, Bayer AG, Frankfurt am Main, Germany

${ }^{5}$ Protección Vegetal-FCA, Universidad Católica de Córdoba (UCC), Córdoba, Argentina

'IFEVA - CONICET - Faculty of Agronomy, Department of Ecology, University of Buenos Aires (UBA), Buenos Aires, Argentina

${ }^{7}$ Instituto Nacional de Investigación Agropecuaria (INIA), Estación

Experimental INIA La Estanzuela, Colonia, Uruguay

${ }^{8}$ Department of Crop Science, Federal University of Rio Grande do Sul, Porto Alegre, RS, Brazil

${ }^{9}$ Plant \& Environmental Sciences Department, University of Copenhagen, Tåstrup, Denmark

Correspondence

Paul Neve, Plant \& Environmental

Sciences Department, University of

Copenhagen, Tåstrup, Denmark.

Email: pbneve@plen.ku.dk

Funding information

Biotechnology and Biological Sciences Research Council, Grant/Award Number: $\mathrm{BB} / \mathrm{N} 022319 / 1$ and BBS/OS/CP/000001

\begin{abstract}
The global invasion, and subsequent spread and evolution of weeds provides unique opportunities to address fundamental questions in evolutionary and invasion ecology. Amaranthus palmeri is a widespread glyphosate-resistant (GR) weed in the USA. Since 2015, GR populations of A. palmeri have been confirmed in South America, raising questions about introduction pathways and the importance of pre- vs. post-invasion evolution of GR traits. We used RAD-sequencing genotyping to characterize genetic structure of populations from Brazil, Argentina, Uruguay and the USA. We also quantified gene copy number of the glyphosate target, 5-enolpyruvyl-3-shikimate phosphate synthase (EPSPS), and the presence of an extrachromosomal circular DNA (eccDNA) replicon known to confer glyphosate resistance in USA populations. Populations in Brazil, Argentina and Uruguay were only weakly differentiated (pairwise $F_{\mathrm{ST}} \leq 0.043$ ) in comparison to USA populations (mean pairwise $F_{\mathrm{ST}}=0.161$, range $=0.068-0.258$ ), suggesting a single major invasion event. However, elevated EPSPS copy number and the EPSPS replicon were identified in all populations from Brazil and Uruguay, but only in a single Argentinean population. These observations are consistent with independent in situ evolution of glyphosate resistance in Argentina, followed by some limited recent migration of the eccDNA-based mechanism from Brazil to Argentina. Taken together, our results are consistent with an initial introduction of $A$. palmeri into South America sometime before the 1980s, and local evolution of GR in Argentina, followed by a secondary invasion of GR A. palmeri with the unique eccDNA-based mechanism from the USA into Brazil and Uruguay during the 2010s.
\end{abstract}

\section{KEYWORDS}

Amaranthus palmeri, herbicide resistance, Palmer amaranth, population genomics, RAD-seq

\section{1 | INTRODUCTION}

The evolution and global spread of herbicide resistance in plant populations provides compelling opportunities to explore fundamental questions in evolutionary (Baucom, 2016; Kreiner et al., 2019) and invasion biology (Bock et al., 2015), whilst also addressing important aspects of herbicide resistance and weed management. The herbicides used for weed control in agriculture impose an intense selection pressure, and the evolution of resistance has been rapid and widespread. In 2021, evolved herbicide resistance is reported in 263 species distributed across 71 countries (Heap, 2021). The global selection for herbicide resistance represents an unparalleled 
human-directed "experiment," providing unique opportunities to study the processes of contemporary plant adaptation.

The observation that herbicide resistance (particularly target site resistance) is conferred by the same point mutations at the same loci in multiple populations of the same species and across multiple species (Powles \& Yu, 2010) is, in itself, evidence for global patterns of convergent evolution. It also suggests that mutational targets for the evolution of resistance are somewhat constrained (Baucom, 2019). Notwithstanding this, questions about the origins of the genetic variation on which selection for resistance is based remain equivocal and may vary depending on an organism-by-pesticide-bymanagement basis (Hawkins et al., 2019). Questions include: do resistance mutations arise from standing genetic variation that exists in weed populations prior to selection, or is evolution of resistance mutation-limited such that adaptation is only possible following the emergence of de novo mutations after the onset of selection? Does resistance arise infrequently (or even as a single occurrence) and subsequently spread via gene flow within and amongst populations, or are there multiple, local evolutionary events (reviewed by Baucom, 2019; Kreiner et al., 2018; Neve et al., 2014)? Similar questions are pertinent in invasion ecology and genetics. Do invasive plant species become established in new areas via single or multiple introductions? Are individuals pre-adapted to their new environments, do they rapidly adapt following invasion via the selection and reassortment of standing genetic variation, or are new arrivals poorly adapted and only able to establish following a lag phase during which adaptive de novo mutations accrue (see Bock et al., 2015)? These questions are relevant when considering the recent arrival of populations of glyphosate-resistant (GR) Amaranthus palmeri (Palmer amaranth) in South America and are the focus of this study.

Several previous studies have sought to establish geographical patterns of herbicide resistance to infer if resistance has evolved via multiple local, independent evolutionary events, or if there has been a single (or a few) localized event(s) and subsequent spread of resistance via natural and human-mediated gene flow. In Alopecurus myosuroides, (Délye et al. (2013) inferred that multiple, independent origins of resistance underpinned the evolution, distribution and spread of resistance to the acetyl Co-A carboxylase (ACCase) herbicides. Délye et al. (2013) have reported the presence of ACCaseconferring resistance mutations in herbarium samples of Alopecurus myosuroides that pre-date the use of those herbicides, providing strong evidence that standing genetic variation may account for the rapid evolution of this type of resistance. In Australia, high frequencies of mutations conferring resistance to acetolactate synthase (ALS) were found to be present in Lolium rigidum populations prior to any herbicide selection (Preston \& Powles, 2002). Together, these studies suggest that standing genetic variation, soft selective sweeps and multiple evolutionary origins of resistance may predominate for common and widespread resistance mechanisms.

The case of glyphosate resistance presents a potentially different evolutionary dynamic. Glyphosate has been used as a nonselective herbicide in global agriculture since the mid-1970s, but unlike in ACCase and ALS herbicides, where resistance became evident only 5-8 years after introduction (Heap, 2014), the first reported case of glyphosate resistance in the USA was in 2001 (VanGessel, 2001), following 25 years of glyphosate use. Under intense selection in the presence of glyphosate-tolerant crops, glyphosate resistance has now evolved in 16 weed species in the USA (Heap, 2021). Several mechanisms of resistance have been reported and/or implicated (Gaines et al., 2019; Sammons \& Gaines, 2014), at least two of which result in over-production of glyphosate's target enzyme, 5-enolpyruvylshikimate 3-phosphate synthase (EPSPS) via mechanisms of gene amplification (Gaines et al., 2019). Notably, Molin et al. (2017) assembled and sequenced BAC libraries from GR A. palmeri to investigate the EPSPS replication and flanking sequence, leading to the discovery that the EPSPS replicon is located within extrachromosomal circular DNA (eccDNA) of over $400 \mathrm{~kb}$ (Molin et al., 2020) tethered to multiple chromosomes within the A. palmeri genome and transmissible at both mitosis and meiosis (Koo et al., 2018).

The time taken for glyphosate resistance to evolve, and the rare genetic mechanisms implicated might suggest that populations were initially mutation-limited, that molecular targets for resistance are rare, and that resistance is more likely to evolve as single or rare events with subsequent spread of resistance via gene flow, mediated by pollen and seed dispersal. Comparing sequences of an amplified EPSPS cassette from GR A. palmeri populations collected from six states in the USA, Molin et al. (2018) found very high levels of sequence similarity. These observations are consistent with a single evolution of this mechanism and subsequent spread throughout the USA. Recent genomic resequencing of eccDNA from multiple GR populations showed very high similarity across the 400-kb EPSPS replicon (Molin et al., 2020). On the other hand, Kreiner et al. (2019), working with the closely related Amaranthus tuberculatus, reported evidence that GR populations in Canada had arisen through invasion of pre-adapted GR genotypes from the USA and via the independent evolution of glyphosate resistance on local genetic backgrounds.

A. palmeri is an annual, dioecious species that is native to the Sonoran Desert of southwestern USA and northern Mexico (Sauer, 1957) but has displayed a profound ability to adapt to colder and/or more humid climates. By 1915, A. palmeri is believed to have spread as far east in the USA as Virginia (Ward et al., 2013) and today it can be found in 39 states (Briscoe Runquist et al., 2019). A. palmeri causes extensive yield loss and increases the cost of production for soybean (Klingaman \& Oliver, 1994) and cotton (MacRae et al., 2013). In corn, A. palmeri can cause up to a $91 \%$ decrease in yield (Massinga et al., 2001).

A. palmeri was recorded as present in Argentina in La Pampa region in 1984 (Covas, 1984), possibly introduced as a contaminant of alfalfa seed (Covas, 1984; Michaud et al., 1988; Montoya et al., 2015). GR A. palmeri was also reported in Brazil and Argentina in 2015 (Carvalho et al., 2015; Heap, 2021). Kaundun et al. (2019) found that glyphosate resistance in a single $A$. palmeri population from Argentina was conferred by a proline 106 to serine mutation in the EPSPS gene, while Palma-Bautista et al. (2019) found a nontargetsite glyphosate resistance mechanism in a different $A$. palmeri population from Argentina. These mechanisms have not been reported 
in A. palmeri from the USA, suggesting independent, local evolution of glyphosate resistance in Argentina. Sequencing of Argentinean A. palmeri populations indicated absence of an ALS target site mutation (Berger et al., 2016) that was later characterized in populations from Brazil with multiple resistance to ALS herbicides and glyphosate (Küpper et al., 2017). A. palmeri was not recorded as present in Uruguay in a comprehensive weed survey conducted between 2005 and 2007 (Rios et al., 2007). Anecdotal evidence from the field suggests that GR A. palmeri was introduced on imported machinery from the USA between 2012 and 2015 in Uruguay (M. Alejandro Garcia pers. comm.) and in Brazil from 2011 and 2014 (Anderson Cavenaghi pers. comm.).

This study used RAD-seq (restriction site-associated DNA sequencing) genotyping (Baird et al., 2008) analyses to compare patterns of genetic structure and connectivity within and between populations of A. palmeri from the USA, Argentina, Brazil and Uruguay. We also conducted qPCR (quantitative polymerase chain reaction)-based assays to measure EPSPS gene copy number and PCR assays to determine the presence of the EPSPS replicon in sampled populations. Together, these data were analysed to infer if $A$. palmeri populations now present in three South American countries were probable recent introductions from the USA and whether there is evidence for a single pre-adapted (GR) introduction; multiple, independent introductions; or local evolution of glyphosate resistance in extant South American populations of the species.

\section{2 | METHODS}

\section{1 | Plant material}

Leaf tissue was sampled from actively growing Amaranthus palmeri plants that were collected at field sites in Brazil (four populations), Argentina (10 populations) and Uruguay (three populations). A population is defined as all plants collected at a discrete sampling location (Table 1). At each sampling location, a single newly emerged leaf was taken from up to 30 individual plants. Plants were selected to ensure that the geographical extent of the field populations was sampled at each location. Individual leaves were placed in sealable plastic bags and labelled with a population code and plant number. A small quantity of silica gel was placed inside each plastic bag to exclude moisture, and bags were stored in darkness. After collection, all leaf material was shipped to the Universidade Federal do Rio Grande do Sul, Porto Alegre, Brazil, for sample processing and DNA extraction.

USA reference populations included KS-S, AZ-S, AZ-R and AZ-S2 reported in Küpper et al. (2018); GA-R and GA-S reported in Culpepper et al. (2006); TN-R reported in Steckel et al. (2008); NC-R reported in Culpepper et al. (2008); and CO-R collected from 10 plants in a sugar beet field in 2015 in Colorado $\left(40.14^{\circ} \mathrm{N}\right.$, $-102.43^{\circ} \mathrm{W}$ ). Plants were grown at Colorado State University and leaf tissue was sampled and immediately frozen in liquid nitrogen for DNA extraction.

\subsection{DNA extraction}

Samples were lyophilized and ground in a TissueLyser II (Qiagen). DNA isolation was performed following a modified cetyltrimethylammonium bromide (CTAB) extraction protocol (Doyle \& Doyle, 1987) and quantified on a Nanodrop spectrophotometer (Thermo Scientific) followed by normalization. DNA from the South American samples was lyophilized and shipped to Colorado State University for resuspension and quantification. DNA for the USA samples was extracted as described in Küpper et al. (2018). All samples were measured for DNA concentration using Qubit (Thermo Fisher Scientific) to normalize to $20 \mathrm{ng} / \mu \mathrm{l}$ in a total volume of $150 \mu \mathrm{l}$ volume to provide $3 \mu \mathrm{g}$ DNA for each sample. Samples were shipped to Floragenex in four 96-well plates with strip caps. Each plate contained 95 samples and one blank, for a total of 380 individual plant DNA samples.

\section{3 | RAD-seq genotyping SNP calling}

RAD-seq was performed by Floragenex using standard methodology (Slavov et al., 2014). Libraries were created using the Pst restriction enzyme and all four plates were sequenced using single 100-bp reads across all four runs of NextSeq 500 (Illumina). Trimmed fastq reads (91 bp) are available at NCBI BioProject accession PRJNA672995. A total of $347,799,399$ good, barcoded reads were generated, with each individual covered by an average of 905,728 reads.

The raw sequenced DNA reads were quality-checked and reviewed using FASTQC (Andrews, 2010). They were then used in the TASSEL-UNEAK version 3.0 network-based reference-free de novo single nucleotide polymorphism (SNP) discovery pipeline (Lu et al., 2013), following the published protocol (Glaubitz et al., 2014) except where noted below. Although UNEAK uses data inefficiently (e.g., reads are trimmed to $64 \mathrm{bp}$ ), its stringent approach to resolving paralogous loci and sequencing errors makes it preferable to other pipelines, when no reference genome is available (Torkamaneh et al., 2016). This analysis was conducted prior to the recent publication of the $A$. palmeri reference genome (Montgomery et al., 2020).

Good reads with barcodes and cut sites were demultiplexed, trimmed and truncated to $64 \mathrm{bp}$ as necessary, and then sorted into unique sequence tags by compiling exactly matching reads. Singleton or rare reads corresponding to five or fewer tags were discarded. Tag pairs were identified by pairwise alignment. Because one tag is usually involved in multiple tag pairs, a network filter was used to identify reciprocal tag pairs, using an error tolerance rate of 0.03 to discard repeats, paralogues and sequencing errors. Reciprocal tags pairs with 1-bp mismatch were considered as SNPs. This leads to a HapMap file, providing a catalogue of SNPs (haplotypes) by population sample, which was filtered to only retain SNPs with a minor allele frequency (MAF) of at least 0.025 and call rate of at least $80 \%$. This resulted in a set of 4,659 SNPs which were used in all population genetic analyses. 


\begin{tabular}{|c|c|c|c|c|c|}
\hline Code & Country & $\begin{array}{l}\text { No. of } \\
\text { plants }\end{array}$ & Location & Collection site & Year \\
\hline ARG-P1 & Argentina & 11 & West Rio Cuarto, Cordoba & Soybeans & 2016 \\
\hline ARG-P2 & Argentina & 8 & Sampacho, Cordoba & Soybeans & 2016 \\
\hline ARG-P3 & Argentina & 15 & Vizcacheras, San Luis & Roadside & 2016 \\
\hline ARG-P4 & Argentina & 9 & Justo Daract, San Luis & Corn & 2016 \\
\hline ARG-P5 & Argentina & 12 & Justo Daract, San Luis & Grain elevator & 2016 \\
\hline ARG-P6 & Argentina & 13 & Pizarro, Cordoba & Soybeans & 2016 \\
\hline ARG-P7 & Argentina & 8 & Pizarro/Valeria, Cordoba & Sorghum & 2016 \\
\hline ARG-P8 & Argentina & 8 & $\begin{array}{l}\text { Las Lomas, Villa Valeria, } \\
\text { Cordoba }\end{array}$ & Corn & 2016 \\
\hline ARG-P9 & Argentina & 8 & $\begin{array}{l}\text { Melideo de La Serna, } \\
\text { Cordoba }\end{array}$ & Soybeans & 2016 \\
\hline ARG-P10 & Argentina & 18 & Rio Quinto, Cordoba & Soybeans & 2016 \\
\hline BRZ-P1 & Brazil & 21 & Tapurah, Mato Grosso & $\begin{array}{c}\text { Soybeans / } \\
\text { cotton }\end{array}$ & 2016 \\
\hline BRZ-P2 & Brazil & 18 & $\begin{array}{l}\text { Ipiranga do Norte, Mato } \\
\text { Grosso }\end{array}$ & $\begin{array}{c}\text { Soybeans / } \\
\text { cotton }\end{array}$ & 2016 \\
\hline BRZ-P3 & Brazil & 21 & $\begin{array}{l}\text { Ipiranga do Norte, Mato } \\
\text { Grosso }\end{array}$ & $\begin{array}{c}\text { Soybeans / } \\
\text { cotton }\end{array}$ & 2016 \\
\hline BRZ-P4 & Brazil & 28 & $\begin{array}{l}\text { Campos de Julio, Mato } \\
\text { Grosso }\end{array}$ & $\begin{array}{c}\text { Soybeans / } \\
\text { cotton }\end{array}$ & 2016 \\
\hline URU-P1 & Uruguay & 19 & Colonia Valdense, Colonia & Corn & 2017 \\
\hline URU-P2 & Uruguay & 17 & Porvenir, Paysandú & Soybeans & 2017 \\
\hline URU-P3 & Uruguay & 16 & $\begin{array}{l}\text { Colonia Tomas Berreta, Rio } \\
\text { Negro }\end{array}$ & Soybeans & 2017 \\
\hline$A Z-R$ & USA & 17 & Buckeye, Arizona & Cotton & 2012 \\
\hline$A Z-S$ & USA & 17 & Sahuarita, Arizona & Desert & 2012 \\
\hline $\mathrm{CO}-\mathrm{R}$ & USA & 14 & Yuma County, Colorado & Sugar beet & 2015 \\
\hline GA-R & USA & 16 & Macon, Georgia & Cotton & 2006 \\
\hline GA-S & USA & 17 & Worth County, Georgia & Cotton & 2004 \\
\hline KS-S & USA & 13 & Ottawa, Kansas & Soybean & 2005 \\
\hline NC-R & USA & 2 & North Carolina & Cotton & 2006 \\
\hline TN-R & USA & 17 & Jackson, Tennessee & Soybean & 2007 \\
\hline AZS-2 & USA & 17 & Tucson, Arizona & Desert & 1981 \\
\hline
\end{tabular}

TABLE 1 Population identifiers and sampling locations for Amaranthus palmeri populations collected in South and North America

\section{4 | RAD-seq data analysis}

We used model-based clustering as implemented in the STRUCTURE program (Falush et al., 2003, 2007; Pritchard et al., 2000) to detect genetic groups and attempt population assignment. The number of genetic groups $(K)$ was varied between 1 and 10 and for each value of $K$ the program was run 10 times, with 1000 burn-in and 10,000 data collection iterations. Runs were then summarized using CLUMPP (Jakobsson \& Rosenberg, 2007) and plausible values of $K$ were identified using the method of Evanno et al. (2005) as implemented in STRUCTURE HARVESTER (Earl \& vonHoldt, 2012). Results for these values were then illustrated using DISTRUCT (Rosenberg, 2004). To further assess the robustness of these results, we ran STRUCTURE assuming larger numbers of groups (up to $K=15$ ) and after subsampling populations in Argentina, Brazil and Uruguay, to avoid biases caused by unbalanced sampling (Meirmans, 2019). To quantify genetic differentiation between populations, we calculated pairwise $F_{\mathrm{ST}}$ values using the EIGENSOFT program (Patterson et al., 2006) and an approach robust to the effects of rare alleles (Bhatia et al., 2013). We also used the smartpca function within EIGENSOFT to perform individual-based principal component analysis (PCA) of population structure. To avoid artefacts caused by linkage disequilibrium, we removed one SNP from each pair with $r^{2} \geq .2$, leaving 4301 SNPs for the PCA. As a crude relative measure of genetic diversity, we also estimated observed heterozygosity $\left(H_{\mathrm{O}}\right)$ for each individual using the --het option of PLINK version 1.9 (Chang et al., 2015; Purcell et al., 2007) and then calculated averages by population and/or country.

In addition to analyses of population structure, we also estimated recent migration rates (i.e., over the last several generations) 
using the Bayesian inference approach BAYESASS (Wilson \& Rannala, 2003) as implemented in the BA3-SNPS program (Mussmann et al., 2019), which was specifically developed for larger genome-wide SNP data sets, such as the one used in this study. As recommended by the general approach and program developers, we ran the program using 5 million iterations, discarding the first 1 million (burnin) and only sampling every 4 th iteration after that (thinning). This was repeated three times using different seeds for the random number generator and the consistency of results was assessed using Mantel tests as implemented in the mantel.rtest function of the ADE4 R package (Thioulouse et al., 2018).

\section{5 | EPSPS copy number qPCR assay and EPSPS replicon-specific marker PCR assay}

A subset of DNA samples from Brazil (three populations, six individuals each), Uruguay (three populations, six individuals each), Argentina (10 populations, six individuals each), GA-S (six individuals) and GA-R (six individuals) was used to measure EPSPS gene copy number and presence of the EPSPS replicon (Molin et al., 2018). Relative EPSPS copy number was measured with $2 \times$ SYBRgreen master mix (Quantabio) using qPCR methods and primer sequences described by Gaines et al. (2010). Previously reported EPSPS cassette markers AW293xAW275, AW516xAW519 and AW216xAW541 (Molin et al., 2018) were used and are here referred to as the EPSPS replicon-specific markers A (1757 bp), B (2352 bp) and C (1544 bp), respectively, while the qPCR primer set for the EPSPS gene from Gaines et al. (2010) was used as a positive control for amplification of the template DNA. The presence or absence of the three EPSPS replicon markers in the same subset of A. palmeri DNA from Brazil, Uruguay, Argentina, GA-S and GA-R was used for a qualitative assessment of the EPSPS replicon in South America compared to the USA. Following evidence suggesting possible migration (BA3-SNPS analysis) from Brazil we re-examined the STRUCTURE plots (Figure 1) and noted that an individual from population ARG-P10 consistently clustered with all individuals sampled from Brazil. This individual was subsequently included for analysis of presence of EPSPS replicon markers. $2 \times$ Econotaq master mix (Lucigen) was used along with the recommended cycling conditions of initial denaturing at $94^{\circ} \mathrm{C}$ for $4 \mathrm{~min}$, followed by $30 \mathrm{cycles}$ of $94^{\circ} \mathrm{C}$ for $30 \mathrm{~s}$, annealing at $55^{\circ} \mathrm{C}$ for $30 \mathrm{~s}$, and an extension period of $72^{\circ} \mathrm{C}$ for $90 \mathrm{~s}$, and final extension at $72^{\circ} \mathrm{C}$ for $5 \mathrm{~min}$.

\section{3 | RESULTS}

\section{1 | Population structure}

Analyses of STRUCTURE results using the method of Evanno et al. (2005) strongly favoured the assignment of three main genetic groups $(K=3)$. However, results for higher values of $K$ were also informative and consistently revealed several patterns (Figure 1). First, individuals from each South American country tended to cluster together, despite the fact that multiple populations were sampled in each country. Second, populations from Argentina consistently clustered in a separate group from those in Brazil and Uruguay, even when $K=3$ was assumed for the entire data set. Populations from the latter two countries also clustered in separate groups for higher values of $K(K>6)$. These interpretations are

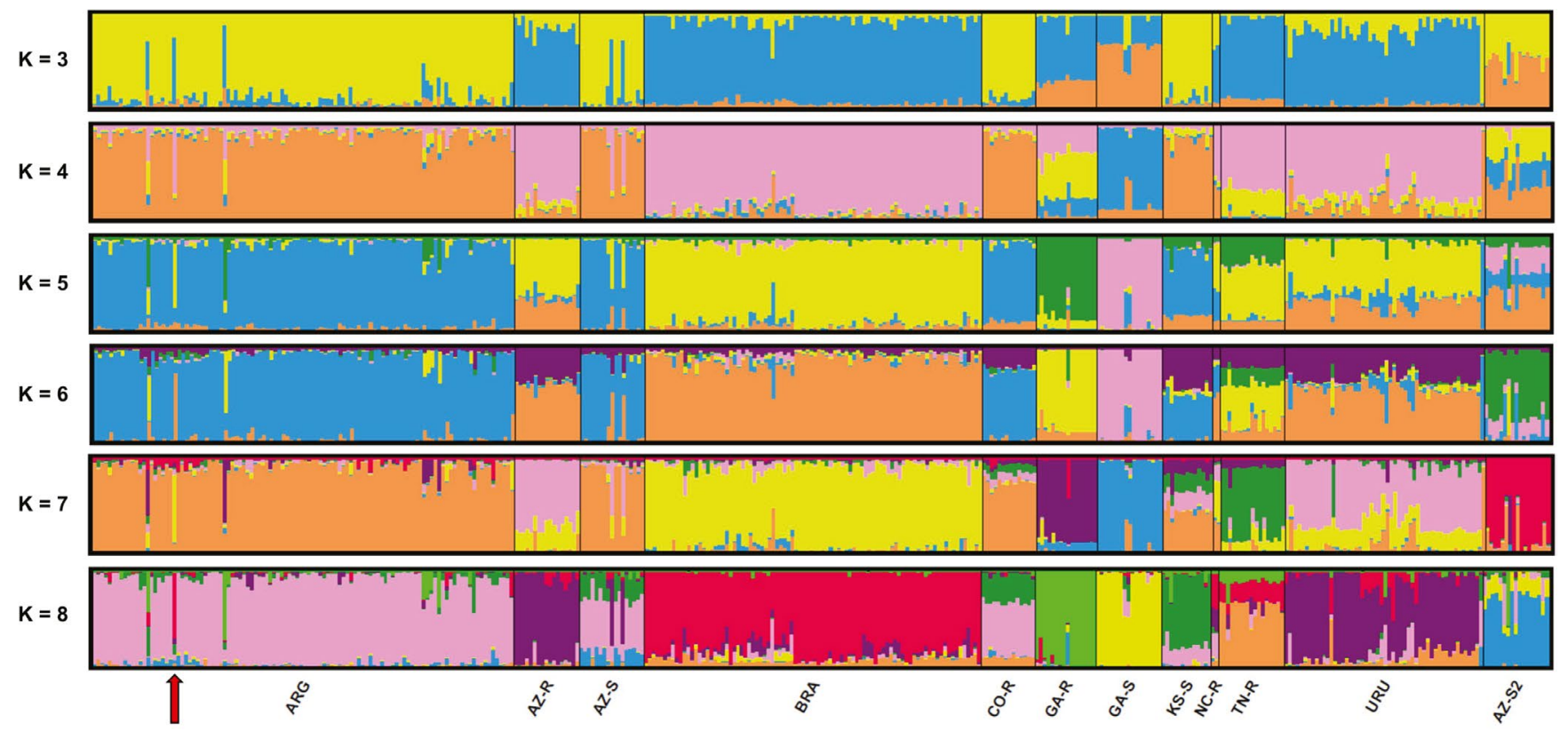

FIGURE 1 Results from model-based clustering using STRUCTURE, with the number of genetic groups varied between 3 and 8 ( $K=3-8)$. The red arrow points to the individual sampled from ARG-P10, which consistently clustered in the same group as all individuals sampled in Brazil and had an elevated EPSPS copy number 
generally supported when data were analysed by PCA (Figure S1), with populations from Brazil and Uruguay tightly clustered on PC1. Overall, there was a high degree of population structure amongst the sampled populations from the USA (mean pairwise $F_{\mathrm{ST}}=0.161$, range $=0.068-0.258$, see Table 1, Figure 1; Figure S1). Populations from Georgia (GA-S and GA-R) and a single Arizona population (AZS2) appear to be strongly differentiated from all other populations by PCA. Regardless of these insights, identifying the exact geographical location of USA Amaranthus palmeri populations that were introduced to South America is not realistic, given the small number of USA populations we sampled.

Pairwise $F_{S T}$ values confirmed the stronger differentiation among the USA populations, particularly GA-R, GA-S, and AZ-S2 (pairwise $F_{S T} \geq 0.123$ ) and provided a further level of nuance to patterns detected using STRUCTURE and PCA (Table 2; Table S1). In contrast, levels of genetic differentiation between populations from the three South American countries were relatively low (pairwise $F_{S T} \leq 0.043$ ), suggesting that either gene flow between established populations is extensive or there was an introduction of $A$. palmeri to the continent from a common source. There were also slightly lower levels of observed heterozygosity within the Argentinean populations compared to those from Brazil and Uruguay (Table S2).

Recent migration rates estimated using the BA3-SNPS program were highly consistent between runs of the program $(r>.99, p<.001$ from Mantel tests). As expected, the average migration rates across the three runs were inversely correlated with pairwise $F_{\mathrm{ST}}$ values calculated at the country level, but this correlation was relatively weak ( $r=-.31, p=.029$ from a Mantel test). More importantly these migration rate estimates provided further insights into possible migration patterns of $A$. palmeri following introduction to South America (Table 3). Comparing the reciprocal magnitudes of migration rates among South American countries suggests that there has been recent migration from Brazil into Argentina and Uruguay (four to five times higher migration rates from Brazil to Uruguay and Argentina). Exploring recent migration at the subpopulation level (Table S3) suggests that the most likely source of Brazilian migration is population BRZ-P2.

\section{2 | EPSPS copy number qPCR assay and EPSPS replicon-specific marker PCR assay}

The GA-R population had high copy number of the EPSPS gene as expected (Table 4) and individuals from GA-S had the expected single copy of EPSPS. All three tested populations from Brazil and Uruguay had high EPSPS copy number (Table 4, fold increase of 56-103). The populations from Argentina had mean relative EPSPS copy number between one- and two-fold higher than the reference (Table 4). The EPSPS replicon-specific markers A, B and C amplified in GA-R individuals but not in GA-S individuals, as expected (Table 4, Figure 2). Similar to GR populations in the USA, all three EPSPS replicon markers amplified in all three populations from Brazil and Uruguay (Table 4, Figure 2). None of the EPSPS replicon-specific markers amplified in the six individuals initially tested from 10 populations from Argentina (Table 4, Figure 2), indicating that these populations do not contain the EPSPS replicon. Based on the evidence suggesting possible migration from Brazil to Argentina, we tested an additional individual from ARG-P10 that showed higher similarity to Brazilian populations in the STRUCTURE plot, even at $K=8$ (Figure 1). All three EPSPS replicon-specific markers amplified from this individual and it had EPSPS copy number of 77 (Table 1), making it the only individual tested from Argentina to test positive for the EPSPS replicon. BA3 analysis suggested that BRZ-P2 is the most likely migration source for ARG-P10 (Table S3).

TAB LE 2 Pairwise $F_{\mathrm{ST}}$ values for all Amaranthus palmeri populations (Argentina, Brazil and Uruguay samples considered as a single population in this analysis)

\begin{tabular}{|c|c|c|c|c|c|c|c|c|c|c|c|c|}
\hline & GA-S & GA-R & NC-R & TN-R & KS-S & CO-R & AZ-S & AZ-R & AZ-S2 & ARG & BRZ & URU \\
\hline GA-R & & 0 & 0.137 & 0.208 & 0.182 & 0.179 & 0.171 & 0.16 & 0.249 & 0.143 & 0.123 & 0.134 \\
\hline NC-R & & & 0 & 0.125 & 0.11 & 0.088 & 0.076 & 0.068 & 0.156 & 0.046 & 0.04 & 0.044 \\
\hline TN-R & & & & 0 & 0.177 & 0.16 & 0.16 & 0.139 & 0.235 & 0.125 & 0.107 & 0.106 \\
\hline KS-S & & & & & 0 & 0.118 & 0.128 & 0.127 & 0.188 & 0.092 & 0.103 & 0.103 \\
\hline AZ-S & & & & & & & 0 & 0.091 & 0.159 & 0.055 & 0.072 & 0.072 \\
\hline AZ-R & & & & & & & & 0 & 0.171 & 0.067 & 0.056 & 0.054 \\
\hline AZ-S2 & & & & & & & & & 0 & 0.127 & 0.144 & 0.147 \\
\hline ARG & & & & & & & & & & 0 & 0.041 & 0.043 \\
\hline
\end{tabular}

Notes: Cells are colour-coded from light green through red to indicate progressively higher $F_{\mathrm{ST}}$ (i.e., increased genetic differentiation between populations). 


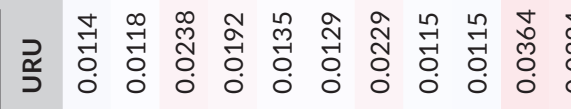

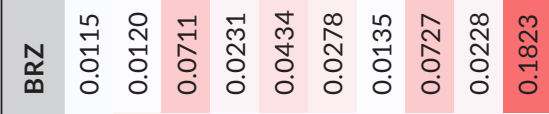

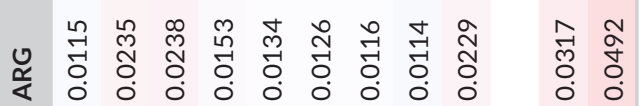

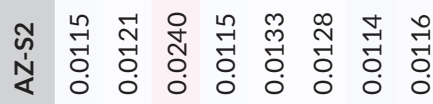

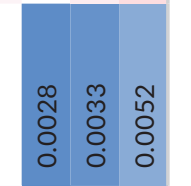

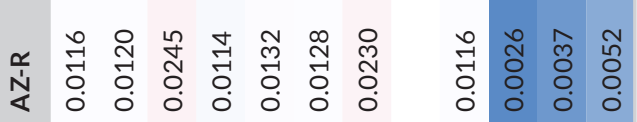

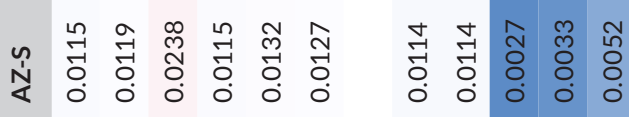

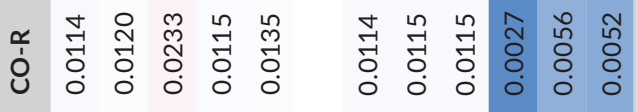

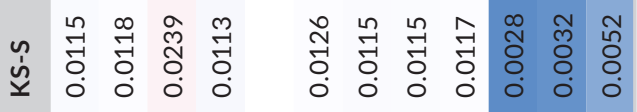

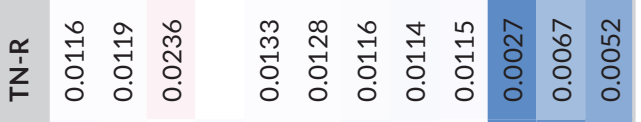

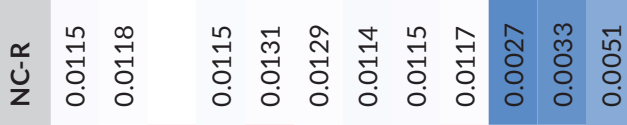

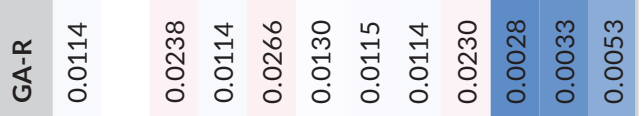

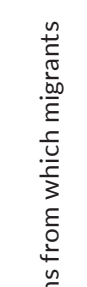

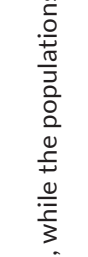




\begin{tabular}{|c|c|c|c|c|c|}
\hline Country & Population & $n$ & $\begin{array}{l}\text { Mean EPSPS gene } \\
\text { copy number }\end{array}$ & SE & $\begin{array}{l}\text { EPSPS eccDNA } \\
\text { replicon markers }\end{array}$ \\
\hline \multirow[t]{2}{*}{ USA } & GA-R & 6 & 125 & 4.1 & + \\
\hline & GA-S & 6 & 1 & 0.0 & - \\
\hline \multirow[t]{3}{*}{ Brazil } & BRZ-P1 & 5 & 75 & 6.3 & + \\
\hline & BRZ-P2 & 6 & 56 & 5.4 & + \\
\hline & BRZ-P3 & 6 & 80 & 7.1 & + \\
\hline \multirow[t]{3}{*}{ Uruguay } & URU-P1 & 6 & 76 & 8.9 & + \\
\hline & URU-P2 & 6 & 75 & 4.9 & + \\
\hline & URU-P3 & 6 & 103 & 3.4 & + \\
\hline \multirow[t]{10}{*}{ Argentina } & ARG-P1 & 6 & 2 & 0.1 & - \\
\hline & ARG-P2 & 6 & 2 & 0.1 & - \\
\hline & ARG-P3 & 1 & 2 & & - \\
\hline & ARG-P4 & 6 & 2 & 0.0 & - \\
\hline & ARG-P5 & 6 & 1 & 0.1 & - \\
\hline & ARG-P6 & 6 & 2 & 0.2 & - \\
\hline & ARG-P7 & 6 & 2 & 0.1 & - \\
\hline & ARG-P8 & 6 & 2 & 0.2 & - \\
\hline & ARG-P9 & 6 & 2 & 0.1 & - \\
\hline & ARG-P10 & 6 & 2 & 0.2 & - \\
\hline
\end{tabular}

TABLE 4 Mean relative EPSPS copy number in Amaranthus palmeri populations from the USA (GA-R and GA-S), Brazil, Uruguay and Argentina, along with presence $(+)$ or absence $(-)$ of the EPSPS eccDNA replicon markers; $S E$, standard error of the mean

${ }^{a} \mathrm{An}$ additional individual from ARG-P10 was included in a subsequent analysis of EPSPS copy number and for presence of EPSPS replicon markers following inference of recent migration from Brazil to Argentina and evidence of clustering of one ARG-P10 individual with all individuals sampled from Brazil. Results are discussed separately in the Results section.

\section{4 | DISCUSSION}

Several agronomic factors have seen Amaranthus palmeri emerge as a major weed of cotton, corn and soybean production systems of the USA over the last 20-30 years (Ward et al., 2013). Many of the same drivers have also been witnessed in South America, coincident with a recent increased incidence of $A$. palmeri in Argentina (Montoya et al., 2015), Brazil (Gonçalves Netto et al., 2019) and Uruguay (Kaspary et al., 2020). In this study, we have attempted to address an obvious and significant question: has GR A. palmeri recently invaded South American cropping systems from the USA, or does the emergence of GR populations represent a similar phenomenon to that seen in the USA, where a relatively minor weed has risen to prominence with changing agronomic practices, high glyphosate selection pressure and in situ evolution of glyphosate resistance?

Using population genetic analyses, we detected relatively low genetic differentiation between $A$. palmeri populations from three South American countries $\left(F_{\mathrm{ST}}<0.05\right)$ in comparison to a much stronger differentiation amongst sampled populations from the USA, though STRUCTURE analyses have assigned populations from Brazil and Uruguay to a different genetic cluster than Argentinean populations. Our analysis of EPSPS gene copy number and EPSPS repliconspecific marker assays indicate that EPSPS gene copy is increased in populations from Brazil and Uruguay and is associated with an eccDNA mechanism similar to the USA A. palmeri populations. The majority of populations from Argentina do not have notably elevated copy number for EPSPS, though we did detect one individual with significantly elevated EPSPS. It is notable that our analyses of population structure and recent migration corroborate this finding and suggest some limited recent migration of GR A. palmeri from Brazil to Argentina.

The history and epidemiology of A. palmeri in Argentina shows that the species was recorded as present in La Pampa province in 1984 (Covas, 1984). Increasing A. palmeri population sizes were evident in a number of fields in Córdoba province by 2005 (Júlian Oliva, pers. comm.), and a growing number of glyphosate control failures were noted, culminating in the confirmation of evolved glyphosate resistance in A. palmeri populations in Argentina (Kaundun et al., 2019; Palma-Bautista et al., 2019). These studies characterized populations from Córdoba, and whereas one of the reports identified the Pro106Ser mutation at the EPSPS target site as the main glyphosate resistance mechanism along with a 1.8-fold higher EPSPS expression (Kaundun et al., 2019), the other established reduced foliar uptake and translocation as the glyphosate resistance mechanisms (Palma-Bautista et al., 2019). While these studies only established the mechanism of glyphosate resistance in two populations, their findings are consistent with our results which indicate that increased EPSPS gene copy number and the presence of associated EPSPS replicon markers are not the predominant mechanism of glyphosate resistance in Argentina. The Pro106Ser target site mutation and reduced glyphosate leaf absorption and translocation have not been documented in GR A. palmeri populations from the 
FIGURE 2 Agarose gel image depicting the qualitative analysis of the EPSPS eccDNA replicon markers A (1757 bp), B (2352 bp) and C (1544 bp), in three representative biological replicates of Amaranthus palmeri from glyphosatesusceptible (S) and glyphosate-resistant (R) populations from Georgia, USA (GA), as well as Brazil, Uruguay and Argentina. Individuals from all populations from Brazil and Uruguay display all three EPSPS replicon markers similar to GA-R individuals, while all tested individuals from the 10 populations from Argentina lacked the EPSPS replicon. The shorter EPSPS amplicon was included as a positive PCR control for the template DNA

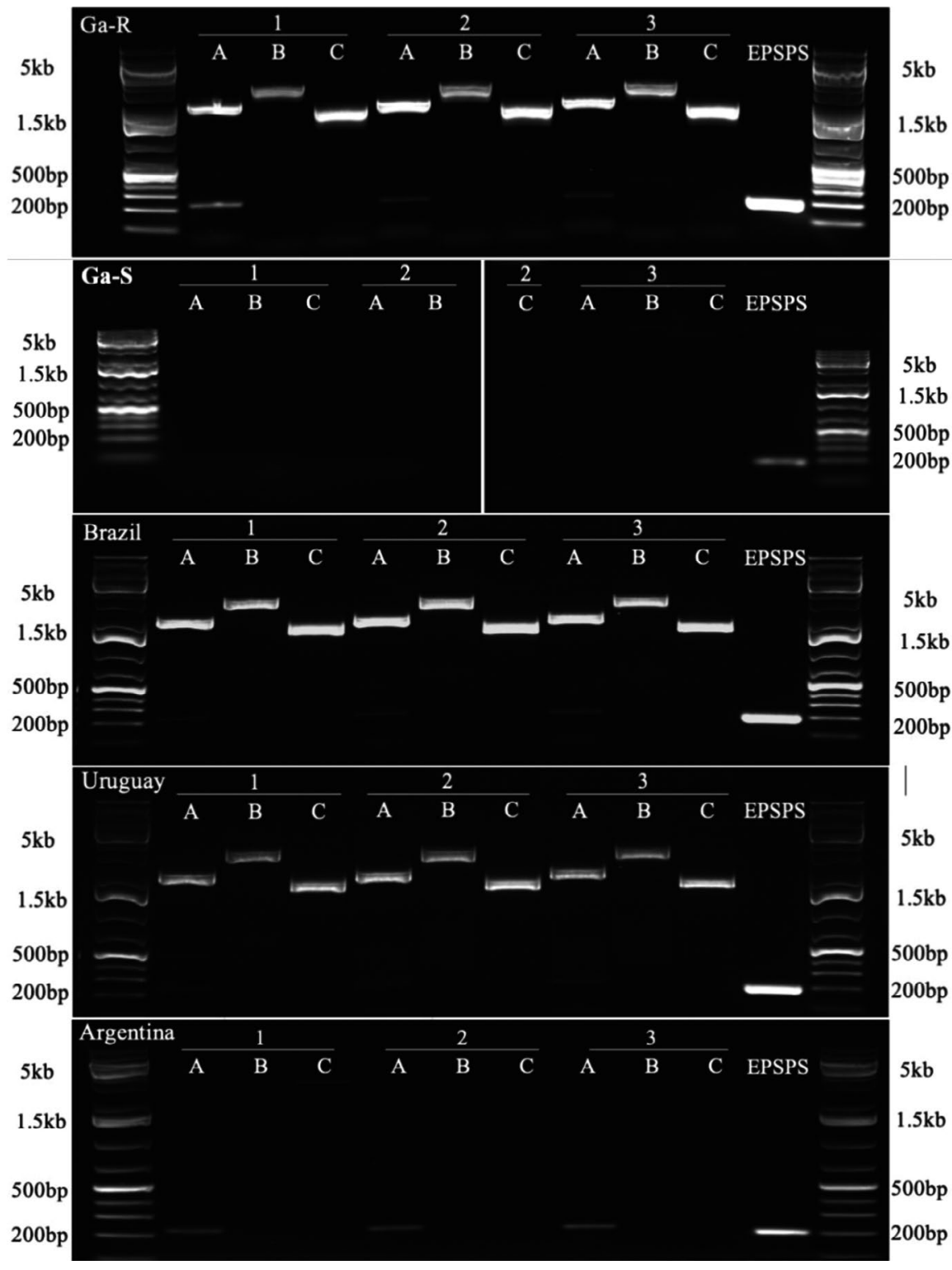

USA (Gaines et al., 2020; Sammons \& Gaines, 2014) and whilst a lack of evidence for these mechanisms in USA populations does not preclude their presence at low frequencies, it seems unlikely that target site or reduced absorption and translocation mechanisms have been introduced from the USA to Argentina. These observations provide strong support for a hypothesis that $A$. palmeri was introduced to Argentina sometime before the 1980s with its subsequent spread and rise to prominence being enabled by changing agronomic practices since the mid-1990s. Independent evolution of glyphosate resistance via mechanisms not present in the North American populations has arisen in Argentina as a result of intense glyphosate selection in glyphosate-tolerant corn and soybean crops. However, there is also evidence for limited and very recent migration of GR A. palmeri populations with the eccDNA mechanism from Brazil into Argentina.

The first confirmed identification of A. palmeri in Brazil was reported in cotton fields in 2015 in Mato Grosso Province (Andrade Júnior et al., 2015). The species was not reported present in Uruguay in 2007 (Rios et al., 2007). A. palmeri populations from Brazil and Uruguay included in our study all exhibited increased EPSPS gene copy number ( $>50$ copies), as well as the presence of EPSPS repliconspecific markers.

Considering the various analyses of the RAD-seq SNP data (STRUCTURE, $F_{\mathrm{ST}}, \mathrm{PCA}$ ) and the molecular genetic analysis of EPSPS replicon markers and copy number, there are contrasting possibilities to account for the invasion (and evolution) of GR A. palmeri in South America. One scenario is that there was a single invasion of glyphosate-susceptible A. palmeri into South America sometime before the 1980s. If this were the case, possibly arising from an initial introduction via contaminated alfalfa seed into Argentina (which would account for the earlier detection of the species in Argentina) and subsequent continental spread to Brazil and Uruguay, then we must account for the quite different mechanisms of glyphosate resistance that have been observed. One explanation is that the discrete glyphosate resistance mechanisms have all evolved in situ under intense glyphosate selection on the same genetic background. 
However, this seems unlikely given the sequence similarity of the EPSPS replicon in Brazilian and Uruguay populations to that found in USA A. palmeri populations.

While this scenario cannot be completely discounted, we suggest that our data are more consistent with a more recent secondary invasion of $A$. palmeri populations from the USA into Brazil and Uruguay. These invading populations from the USA were GR, with that resistance being conferred by the eccDNA EPSPS replicon. We propose that the number of plants/propagules invading from the USA with the eccDNA EPSPS replicon was very small (given the weak differentiation between South American countries) and that there has been a widespread and rapid selective sweep of that mechanism in Brazil and Uruguay on the genomic background of previously invaded populations from the USA. This has been followed by some very recent migration of this GR A. palmeri into Argentina. There is evidence for recent introduction of $A$. palmeri seed on farm machinery imported into Uruguay (Álvarez Luzardo et al., 2017) and a similar route of introduction is possible in Brazil.

A final intriguing, though highly speculative possibility is that the eccDNA replicon was recently introduced into Brazil and Uruguay from the USA and introgressed into the common South American genetic background for A. palmeri via some mechanism of horizontal gene transfer (HGT). Various mechanisms for HGT have been proposed for plants (Gao et al., 2014) and HGT is well established as a mechanism for the evolution and spread of antimicrobial resistance (e.g., Bansal \& Meyer, 2002). The eccDNA replicon is a potential candidate for HGT due to its incredibly high sequence homogeneity (fewer than 10 variants in $400 \mathrm{~kb}$ of eccDNA sequence) among multiple, geographically distant populations of A. palmeri in the USA (Molin, Patterson, et al., 2020) that in at least some cases show population genetic divergence (Küpper et al., 2018). The probability of the identical 400-kb eccDNA sequence forming independently in multiple populations seems less likely than either (i) a small number of introduced plants with the eccDNA followed by a selective sweep for glyphosate resistance or (ii) HGT that enables rapid spatial movement of the eccDNA replicon into new populations.

Our analyses have not been able to definitively answer questions about routes and modes of introduction of A. palmeri into South America. The recent rapid expansion of the species range in North America and the propensity for the evolution and spread of glyphosate resistance clearly demonstrate the extraordinary capacity of this species for rapid adaptation in agroecosystems. It seems highly likely that A. palmeri invaded into South America from the USA, via at least two invasion events. It certainly seems that both the Pro106Ser target site mutation in EPSPS and reduced glyphosate absorption and translocation have evolved locally in Argentina, whilst the eccDNAbased mechanism more likely occurs as a result of the very recent introduction of this intriguing and rare genetic mechanism from the USA and its rapid selection and spread under selection.

\section{ACKNOWLEDGEMENTS}

This work was funded by a Biotechnology \& Biological Sciences Research (BBSRC) Council Global Challenge Research Fund Impact
Accelerator award to P.N. At the time of receipt P.N. and T.A.G. were also in receipt of a BBSRC USA-UK international partnering award (BB/N022319/1). P.N. and G.T.S. were also funded by the Smart Crop Protection (SCP) strategic programme (BBS/OS/CP/000001) funded through the BBSRC's Industrial Strategy Challenge Fund. The authors are grateful to Dionisio L. P. Gazziero (EMBRAPA), Anderson L. Cavenaghi (UNIVAG) and Rogaciano Arruda (INDEA-MT) for field collection of leaf tissue in Brazil.

\section{AUTHOR CONTRIBUTIONS}

T.G., G.T.S., M.V.A., A.M. Jr and P.N. conceived and designed the research. A.K., T.G., J.O., M.V.A., M.A.G. and A.M. Jr coordinated national collection and sampling of plant and seed populations. T.G., A.K., C.S. and A.M. Jr performed laboratory work. G.T.S. and D.H. performed bioinformatic and population genetic analyses. T.G., G.T.S. and P.N. wrote the manuscript. All co-authors contributed to paper editing and approved the final version of the manuscript.

\section{DATA AVAILABILITY STATEMENT}

Sequence data have been submitted to the NCBI database under accession nos. SRR13337738-SRR13338117 for BioSamples SAMN17191355-SAMN17191734, under BioProject PRJNA672995 (Amaranthus palmeri RAD-Seq genotyping) and SRA Study SRP299915. SNP haplotype data are available at the digital repository, Mountain Scholar, http://dx.doi.org/10.25675/10217/232637.

\section{ORCID}

Todd A. Gaines (D) https://orcid.org/0000-0003-1485-7665

Crystal D. Sparks (D) https://orcid.org/0000-0002-6674-8447

Martin M. Vila-Aiub (D) https://orcid.org/0000 00032118 290X

Paul Neve (D) https://orcid.org/0000-0002-3136-5286

\section{REFERENCES}

Álvarez Luzardo, E., De Vries Carlotta, J., \& Gabriel Long, A. (2017). Evaluación de estrategias para el control químico de Amaranthus palmeri S. Wats en pre emergencia de soja. (Evaluation of strategies for the chemical control of Amaranthus palmeri S. Wats in soybean preemergence, Spanish). Graduate thesis. Universidad de la República (Uruguay). Facultad de Agronomía.

Andrade Júnior, E., Cavaenaghi, A., Guimarães, S., \& Carvalho, S. (2015). Primeiro relato de Amaranthus palmeri no Brasil em áreas agrícolas no estado de Mato Grosso (First report of Amaranthus palmeri in Brazil in agricultural areas in the state of Mato Grosso, Portuguese). Circular Técnica IMA-MT, 19, 1-8.

Andrews, S. (2010). Babraham Bioinformatics, Babraham Institute, . FASTQC: A quality control tool for high throughput sequence data. (https://www.bioinformatics.babraham.ac.uk/projects/fastq cFastQC

Baird, N. A., Etter, P. D., Atwood, T. S., Currey, M. C., Shiver, A. L., Lewis, Z. A., Selker, E. U., Cresko, W. A., \& Johnson, E. A. (2008). Rapid SNP discovery and genetic mapping using sequenced RAD markers. PLoS One, 3, e3376.-https://doi.org/10.1371/journal.pone. 0003376

Bansal, A. K., \& Meyer, T. E. (2002). Evolutionary analysis by wholegenome comparisons. Journal of Bacteriology, 184, 2260-2272. https://doi.org/10.1128/JB.184.8.2260-2272.2002 
Baucom, R. S. (2016). The remarkable repeated evolution of herbicide resistance. American Journal of Botany, 103, 181-183. https://doi. org/10.3732/ajb.1500510

Baucom, R. S. (2019). Evolutionary and ecological insights from herbicideresistant weeds: what have we learned about plant adaptation, and what is left to uncover? New Phytologist, 223, 68-82. https://doi. org/10.1111/nph.15723

Berger, S., Madeira, P. T., Ferrell, J., Gettys, L., Morichetti, S., Cantero, J. J., \& Nuñez, C. (2016). Palmer amaranth (Amaranthus palmeri) identification and documentation of ALS-resistance in Argentina. Weed Science, 64, 312-320.

Bhatia, G., Patterson, N., Sankararaman, S., \& Price, A. L. (2013). Estimating and interpreting FST: the impact of rare variants. Genome Research, 23, 1514-1521. https://doi.org/10.1101/gr.154831.113

Bock, D. G., Caseys, C., Cousens, R. D., Hahn, M. A., Heredia, S. M., Hübner, S., Turner, K. G., Whitney, K. D., \& Rieseberg, L. H. (2015). What we still don't know about invasion genetics. Molecular Ecology, 24, 2277-2297. https://doi.org/10.1111/mec.13032

Briscoe Runquist, R. D., Lake, T., Tiffin, P., \& Moeller, D. A. (2019). Species distribution models throughout the invasion history of Palmer amaranth predict regions at risk of future invasion and reveal challenges with modeling rapidly shifting geographic ranges. Scientific Reports, 9, 2426.

Carvalho, S., Goncalves Netto, A., Nicolai, M., Cavenaghi, A., LopezOvejero, R., \& Christoffoleti, P. (2015). Detection of glyphosateresistant Palmer Amaranth (Amaranthus palmeri) in agricultural areas of Mato Grosso, Brazil. Planta Daninha, 33, 579-586. https:// doi.org/10.1590/S0100-83582015000300020

Chang, C. C., Chow, C. C., Tellier, L. C., Vattikuti, S., Purcell, S. M., \& Lee, J. J. (2015). Second-generation PLINK: rising to the challenge of larger and richer datasets. GigaScience, 4(1), 10047-13748. https:// doi.org/10.1186/s13742-015-0047-8

Covas, G. (1984). Las especies de Amaranthus L., Amaranthaceae, nativas o naturalizadas en la Provincia de La Pampa. Apuntes Fl. Pampa, 8486, 333-341.

Culpepper, A. S., Grey, T. L., Vencill, W. K., Kichler, J. M., Webster, T. M., Brown, S. M., \& Hanna, W. W. (2006). Glyphosate-resistant Palmer amaranth (Amaranthus palmeri) confirmed in Georgia. Weed Science, 54, 620-626.

Culpepper, A. S., Whitaker, J., MacRae, A., \& York, A. (2008). Distribution of glyphosate-resistant Palmer amaranth (Amaranthus palmeri) in Georgia and North Carolina during 2005 and 2006. Journal of Cotton Science, 12, 306-310.

Délye, C., Deulvot, C., \& Chauvel, B. (2013). DNA analysis of herbarium specimens of the grass weed Alopecurus myosuroides reveals herbicide resistance pre-dated herbicides. PLoS One, 8, e75117. https:// doi.org/10.1371/journal.pone.0075117

Délye, C., Jasieniuk, M., \& Le Corre, V. (2013). Deciphering the evolution of herbicide resistance in weeds. Trends in Genetics, 29, 649-658. https://doi.org/10.1016/j.tig.2013.06.001

Doyle, J. J., \& Doyle, J. L. (1987). A rapid DNA isolation procedure for small quantities of fresh leaf tissue. Phytochemical Bulletin, 19, 11-15.

Earl, D. A., \& vonHoldt, B. M. (2012). StRUCTURE HARVESTER: A website and program for visualizing STRUCTURE output and implementing the Evanno method. Conservation Genetics Resources, 4, 359-361. https://doi.org/10.1007/s12686-011-9548-7

Evanno, G., Regnaut, S., \& Goudet, J. (2005). Detecting the number of clusters of individuals using the software STRUCTURE: a simulation study. Molecular Ecology, 14, 2611-2620. https://doi. org/10.1111/j.1365-294X.2005.02553.x

Falush, D., Stephens, M., \& Pritchard, J. K. (2003). Inference of population structure using multilocus genotype data: linked loci and correlated allele frequencies. Genetics, 164, 1567-1587. https://doi. org/10.1093/genetics/164.4.1567
Falush, D., Stephens, M., \& Pritchard, J. K. (2007). Inference of population structure using multilocus genotype data: dominant markers and null alleles. Molecular Ecology Notes, 7, 574-578. https://doi. org/10.1111/j.1471-8286.2007.01758.x

Gaines, T. A., Duke, S. O., Morran, S., Rigon, C. A. G., Tranel, P. J., Küpper, A., \& Dayan, F. E. (2020). Mechanisms of evolved herbicide resistance. Journal of Biological Chemistry, 295, 10307-10330. https:// doi.org/10.1074/jbc.REV120.013572

Gaines, T. A., Patterson, E. L., \& Neve, P. (2019). Molecular mechanisms of adaptive evolution revealed by global selection for glyphosate resistance. New Phytologist, 223, 1770-1775. https://doi. org/10.1111/nph.15858

Gaines, T. A., Zhang, W., Wang, D., Bukun, B., Chisholm, S. T., Shaner, D. L., Nissen, S. J., Patzoldt, W. L., Tranel, P. J., Culpepper, A. S., Grey, T. L., Webster, T. M., Vencill, W. K., Sammons, R. D., Jiang, J., Preston, C., Leach, J. E., \& Westra, P. (2010). Gene amplification confers glyphosate resistance in Amaranthus palmeri. Proceedings of the National Academy of Sciences of the United States of America, 107, 1029-1034. https://doi.org/10.1073/pnas.09066 49107

Gao, C., Ren, X., Mason, A. S., Liu, H., Xiao, M., Li, J., \& Fu, D. (2014). Horizontal gene transfer in plants. Functional \& Integrative Genomics, 14, 23-29. https://doi.org/10.1007/s10142-013-0345-0

Glaubitz, J. C., Casstevens, T. M., Lu, F., Harriman, J., Elshire, R. J., Sun, Q., \& Buckler, E. S. (2014). TASSEL-GBS: A high capacity genotyping by sequencing analysis pipeline. PLoS One, 9, e90346. https://doi. org/10.1371/journal.pone.0090346

Gonçalves Netto, A., Nicolai, M., Carvalho, S., Malardo, M., LópezOvejero, R., \& Christoffoleti, P. (2019). Control of ALS-and EPSPSresistant Amaranthus palmeri by alternative herbicides applied in PRE-and POST-emergence. Planta Daninha, 37, e019212505. https://doi.org/10.1590/s0100-83582019370100109.

Hawkins, N. J., Bass, C., Dixon, A., \& Neve, P. (2019). The evolutionary origins of pesticide resistance. Biological Reviews, 94, 135-155. https://doi.org/10.1111/brv.12440

Heap, I. (2014). Global perspective of herbicide-resistant weeds. Pest Management Science, 70, 1306-1315. https://doi.org/10.1002/ ps.3696

Heap, I. (2021). The international survey of herbicide resistant weeds. www.weedscience.com. Accessed February 17, 2021.

Jakobsson, M., \& Rosenberg, N. A. (2007). CLUMPP: a cluster matching and permutation program for dealing with label switching and multimodality in analysis of population structure. Bioinformatics, 23, 18011806. https://doi.org/10.1093/bioinformatics/btm233

Kaspary, T. E., Garcia, A., Marques, S., Cabrera, O., Garcia, E., \& Garcia, R. (2020). Identification, ocurrence and management of herbicide resistant pigweeds in Uruguay (Identificación de ocurrencia y manejo de yuyos colorados (Amaranthus spp.) resistentes a herbicidas en Uruguay, Spanish). Revista INIA Uruguay, 62, 50-54.

Kaundun, S. S., Jackson, L. V., Hutchings, S.-J., Galloway, J., Marchegiani, E., Howell, A., Carlin, R., Mcindoe, E., Tuesca, D., \& Moreno, R. (2019). Evolution of target-site resistance to glyphosate in an Amaranthus palmeri population from Argentina and its expression at different plant growth temperatures. Plants, 8, 512. https://doi. org/10.3390/plants8110512

Klingaman, T. E., \& Oliver, L. R. (1994). Palmer amaranth (Amaranthus palmeri) interference in soybeans (Glycine max). Weed Science, 42, 523-527.

Koo, D.-H., Molin, W. T., Saski, C. A., Jiang, J., Putta, K., Jugulam, M., \& Gill, B. S. (2018). Extrachromosomal circular DNA-based amplification and transmission of herbicide resistance in crop weed Amaranthus palmeri. Proceedings of the National Academy of Sciences, 115, 3332-3337.

Kreiner, J. M., Giacomini, D. A., Bemm, F., Waithaka, B., Regalado, J., Lanz, C., \& Wright, S. I. (2019). Multiple modes of convergent 
adaptation in the spread of glyphosate-resistant Amaranthus tuberculatus. Proceedings of the National Academy of Sciences USA, 116, 21076-21084.

Kreiner, J. M., Stinchcombe, J. R., \& Wright, S. I. (2018). Population genomics of herbicide resistance: adaptation via evolutionary rescue. Annual Review of Plant Biology, 69, 611-635. https://doi. org/10.1146/annurev-arplant-042817-040038

Küpper, A., Borgato, E. A., Patterson, E. L., Netto, A. G., Nicolai, M. Carvalho, S. J., \& Christoffoleti, P. J. (2017). Multiple resistance to glyphosate and acetolactate synthase inhibitors in Palmer amaranth (Amaranthus palmeri) identified in Brazil. Weed Science, 65, 317-326.

Küpper, A., Manmathan, H. K., Giacomini, D., Patterson, E. L., McCloskey, W. B., \& Gaines, T. A. (2018). Population genetic structure in glyphosate-resistant and-susceptible Palmer amaranth (Amaranthus palmeri) populations using genotyping-by-sequencing (GBS). Frontiers in Plant Science, 9, 29. https://doi.org/10.3389/ fpls.2018.00029

Lu, F., Lipka, A. E., Glaubitz, J., Elshire, R., Cherney, J. H., Casler, M. D., Buckler, E. S., \& Costich, D. E. (2013). Switchgrass genomic diversity, ploidy, and evolution: novel insights from a network-based SNP discovery protocol. PLoS Genetics, 9, e1003215. https://doi. org/10.1371/journal.pgen.1003215

MacRae, A., Webster, T., Sosnoskie, L., Culpepper, A., \& Kichler, J. (2013). Cotton yield loss potential in response to length of Palmer amaranth (Amaranthus palmeri) interference. Journal of Cotton Science, 17, 227-232.

Massinga, R. A., Currie, R. S., Horak, M. J., \& Boyer, J. Jr (2001). Interference of Palmer amaranth in corn. Weed Science, 49, 202208. https://doi.org/10.1614/0043-1745(2001)049(0202:IOPAI C)2.0.CO;2

Meirmans, P. G. (2019). Subsampling reveals that unbalanced sampling affects STRUCTURE results in a multi-species dataset. Heredity, 122, 276-287. https://doi.org/10.1038/s41437-018-0124-8

Michaud, R., Lehman, W., \& Rumbaugh, M. (1988). World distribution and historical development. Alfalfa and Alfalfa Improvement, 29, 25-91.

Molin, W. T., Patterson, E. L., \& Saski, C. A. (2020). Homogeneity among glyphosate-resistant Amaranthus palmeri in geographically distant locations. PLoS One, 15, e0233813. https://doi.org/10.1371/journ al.pone. 0233813

Molin, W. T., Wright, A. A., Lawton-Rauh, A., \& Saski, C. A. (2017). The unique genomic landscape surrounding the EPSPS gene in glyphosate resistant Amaranthus palmeri: a repetitive path to resistance. BMC Genomics, 18, 91. https://doi.org/10.1186/s1286 4-016-3336-4

Molin, W. T., Wright, A. A., VanGessel, M. J., McCloskey, W. B., Jugulam, M., \& Hoagland, R. E. (2018). Survey of the genomic landscape surrounding the 5-enolpyruvylshikimate-3-phosphate synthase (EPSPS) gene in glyphosate-resistant Amaranthus palmeri from geographically distant populations in the United States. Pest Management Science, 74, 1109-1117.

Molin, W. T., Yaguchi, A., Blenner, M. A., \& Saski, C. A. (2020). The eccDNA Replicon: A heritable, extra-nuclear vehicle that enables gene amplification and glyphosate resistance in Amaranthus palmeri. The Plant Cell, 32, 2132-2140.

Montgomery, J. S., Giacomini, D., Waithaka, B., Lanz, C., Murphy, B. P., Campe, R., Lerchl, J., Landes, A., Gatzmann, F., Janssen, A. Antonise, R., Patterson, E., Weigel, D., \& Tranel, P. J. (2020). Draft genomes of Amaranthus tuberculatus, Amaranthus hybridus and Amaranthus palmeri. Genome Biology and Evolution, 12, 1988-1993. https://doi.org/10.1093/gbe/evaa177

Montoya, A. J. C., Garay, A. J. A., \& Cervellini, A. J. M. (2015) Amarantáceas en la Región Semiárida Central Argentina: La Pampa y San Luis. EEA INTA Anguil "Ing. Agr. Guillermo Covas", Ediciones INTA, ISBN, 0325-2167.
Mussmann, S. M., Douglas, M. R., Chafin, T. K., \& Douglas, M. E. (2019). BA3-SNPs: Contemporary migration reconfigured in BayesAss for next-generation sequence data. Methods in Ecology and Evolution, 10, 1808-1813. https://doi.org/10.1111/2041-210X.13252

Neve, P., Busi, R., Renton, M., \& Vila-Aiub, M. M. (2014). Expanding the eco-evolutionary context of herbicide resistance research. Pest Management Science, 70, 1385-1393. https://doi.org/10.1002/ ps.3757

Palma-Bautista, C., Torra, J., Garcia, M. J., Bracamonte, E., RojanoDelgado, A. M., Alcántara-de la Cruz, R., \& De Prado, R. (2019). Reduced absorption and impaired translocation endows glyphosate resistance in Amaranthus palmeri harvested in glyphosate-resistant soybean from Argentina. Journal of Agricultural and Food Chemistry, 67, 1052-1060.

Patterson, N., Price, A. L., \& Reich, D. (2006). Population structure and eigenanalysis. PLoS Genetics, 2, e190. https://doi.org/10.1371/ journal.pgen.0020190

Powles, S. B., \& Yu, Q. (2010). Evolution in action: Plants resistant to herbicides. Annual Review of Plant Biology, 61, 317-347. https://doi. org/10.1146/annurev-arplant-042809-112119

Preston, C., \& Powles, S. B. (2002). Evolution of herbicide resistance in weeds: Initial frequency of target site-based resistance to acetolactate synthase-inhibiting herbicides in Lolium rigidum. Heredity, 88 , 8-13. https://doi.org/10.1038/sj.hdy.6800004

Pritchard, J. K., Stephens, M., \& Donnelly, P. (2000). Inference of population structure using multilocus genotype data. Genetics, 155, 945959. https://doi.org/10.1093/genetics/155.2.945

Purcell, S., Neale, B., Todd-Brown, K., Thomas, L., Ferreira, M. A. R., Bender, D., Maller, J., Sklar, P., de Bakker, P. I. W., Daly, M. J., \& Sham, P. C. (2007). PLINK: a tool set for whole-genome association and population-based linkage analyses. The American Journal of Human Genetics, 81, 559-575. https://doi.org/10.1086/519795

Rios, A., Fernández, G., Collares, L., \& García, A. (2007). Comunidades de malezas asociadas a los sistemas de siembra directa en Uruguay. Paper presented at the Congreso de la Sociedad Española de Malherbología (11., 2007, Albacete, ES). SEMh

Rosenberg, N. A. (2004). DISTRUCT: a program for the graphical display of population structure. Molecular Ecology Notes, 4, 137-138. https://doi.org/10.1046/j.1471-8286.2003.00566.x

Sammons, D. R., \& Gaines, T. A. (2014). Glyphosate resistance: State of knowledge. Pest Management Science, 70, 1367-1377. https://doi. org/10.1002/ps.3743

Sauer, J. (1957). Recent migration and evolution of the dioecious Amaranths. Evolution, 11, 11-31. https://doi.org/10.1111/ j.1558-5646.1957.tb02872.x

Slavov, G. T., Nipper, R., Robson, P., Farrar, K., Allison, G. G., Bosch, M., \& Jensen, E. (2014). Genome-wide association studies and prediction of 17 traits related to phenology, biomass and cell wall composition in the energy grass Miscanthus sinensis. New Phytologist, 201, 1227-1239.

Steckel, L. E., Main, C. L., Ellis, A. T., \& Mueller, T. C. (2008). Palmer amaranth (Amaranthus palmeri) in Tennessee has low level glyphosate resistance. Weed Technology, 22, 119-123. https://doi.org/10.1614/ WT-07-061.1

Thioulouse, J., Dray, S., Dufour, A.-B., Siberchicot, A., Jombart, T., \& Pavoine, S. (2018). Multivariate analysis of ecological data with ade4. Springer.

Torkamaneh, D., Laroche, J., \& Belzile, F. (2016). Genome-wide SNP calling from genotyping by sequencing (GBS) data: a comparison of seven pipelines and two sequencing technologies. PLoS One, 11, e0161333. https://doi.org/10.1371/journal.pone.0161333

VanGessel, M. J. (2001). Glyphosate-resistant horseweed from Delaware. Weed Science, 49, 703-705. https://doi.org/10.1614/00431745(2001)049(0703:RPRHFD)2.0.CO;2

Ward, S. M., Webster, T. M., \& Steckel, L. E. (2013). Palmer amaranth (Amaranthus palmeri): a review. Weed Technology, 27, 12-27. 
Wilson, G. A., \& Rannala, B. (2003). Bayesian inference of recent migration rates using multilocus genotypes. Genetics, 163, 1177-1191. https://doi.org/10.1093/genetics/163.3.1177

\section{SUPPORTING INFORMATION}

Additional supporting information may be found in the online version of the article at the publisher's website.
How to cite this article: Gaines, T. A., Slavov, G. T., Hughes, D., Küpper, A., Sparks, C., Oliva, J., Vila-Aiub, M., Garcia, M. A., Merotto, A. Jr, \& Neve, P. (2021). Investigating the origins and evolution of a glyphosate-resistant weed invasion in South America. Molecular Ecology, 00, 1-13. https://doi. org/10.1111/mec.16221 